\title{
Deficiencia de glucosa 6 fosfato deshidrogenasa en niños. Caso clínico
}

\author{
PATRICIA VERDUGO L. ${ }^{1}$, MARLENE CALVANESE T. ${ }^{2}$, \\ DIEGO RODRÍGUEZ V. ${ }^{3}$, CASSANDRA CÁRCAMO C. ${ }^{4}$ \\ 1. Pediatra Hematólogo Oncólogo Clínica Santa María, Hospital Roberto del Río. \\ 2. Pediatra Clínica Santa María. \\ 3. Médico Cirujano. \\ 4. Interna Medicina, Universidad Del Desarrollo.
}

\begin{abstract}
Glucose-6-phosphate dehydrogenase deficiency in children. A Case report

Introduction: Glucose-6-phosphate dehydrogenase deficiency (G6PD deficiency) is the most common red blood cell (RBC) enzyme disorder. The decrease as well as the absence of the enzyme increase RBC vulnerability to oxidative stress caused by exposure to certain medications or intake of fava beans. Among the most common clinical manifestations of this condition, acute hemolysis, chronic hemolysis, neonatal hyperbilirubinemia, and an asymptomatic form are observed. Objective: To analyze the case of a child who presented hemolytic crisis due to favism. Case report: A 2 year and 7 month old boy with a history of hyperbilirubinemia during the newborn period with no apparent cause, no family history of hemolytic anemia or parental consanguinity. He presented a prolonged neonatal jaundice and severe anemia requiring $\mathrm{RBC}$ transfusion. An intake of fava beans $48 \mathrm{~h}$ prior to onset of symptoms was reported. G6PD qualitative determination was compatible with this enzyme deficiency. Conclusion: G6PD deficiency can be highly variable in its clinical presentation, so it is necessary to keep it in mind during the diagnosis of hemolytic anemia at any age.

(Key words: Favism, Glucose-6-phosphate dehydrogenase deficiency, Acute Hemolysis, Neonatal Jaundice, Hemolytic Anemia).

Rev Chil Pediatr 2014; 85 (1): 74-79
\end{abstract}

\section{RESUMEN}

Introducción: La deficiencia de la glucosa 6-fosfato deshidrogenasa (G6PD) es el trastorno enzimático más frecuente del glóbulo rojo (GR). Tanto la disminución como la ausencia de la enzima aumentan la vulnerabilidad del GR al estrés oxidativo provocado por algunos fármacos o la ingesta de habas. Sus manifestaciones clínicas más frecuentes son hemolisis aguda, hemolisis crónica, hiperbilirrubinemia neonatal, y una forma asintomática. Objetivo: Presentar el caso de un niño que debutó como crisis hemolítica debida a favismo.

Recibido el 9 de diciembre de 2012, devuelto para corregir el 17 de mayo de 2013, segunda versión 22 de julio de 2013, tercera versión 13 de noviembre de 2013, aceptado para publicación el 13 de enero de 2014.

Este trabajo cumple con los requisitos sobre consentimiento /asentimiento informado, comité de ética, financiamiento, estudios animales y sobre la ausencia de conflictos de intereses según corresponda.

Correspondencia a:

Dra. Patricia Verdugo L.

E-mail: pverdugo33@hotmail.com 
Caso clínico: Varón 2 años 7 meses con antecedente de hiperbilirrubinemia en el período neonatal sin causa evidente, sin historia familiar de anemia hemolítica ni de consanguinidad paterna. Debutó con un cuadro de ictericia y anemia severa que requirió transfusión de GR. Como antecedente anamnéstico se detectó la ingesta de habas $48 \mathrm{~h}$ previo al inicio de los síntomas. La determinación cualitativa de G6PD fue compatible con deficiencia de esta enzima. Conclusión: La deficiencia de G6PD puede ser muy variable en su expresión clínica, por lo cual es necesario tenerla presente dentro del diagnóstico diferencial de las anemias hemolíticas a toda edad.

(Palabras clave: Favismo, Deficiencia Glucose-6-fosfato deshidrogenasa, Hemólisis Aguda, Ictericia Neonatal, Anemia Hemolítica).

Rev Chil Pediatr 2014; 85 (1): 74-79

\section{Introducción}

La deficiencia de glucosa 6-fosfato deshidrogenasa (G6PD) es la anomalía enzimática del glóbulo rojo (GR) más frecuente en todo el mundo ${ }^{1-4}$, aunque en nuestra población es poco habitual. En Asia, África y zona del Mediterráneo su prevalencia se relaciona con la distribución geográfica de la malaria lo que ha llevado a plantear que los portadores de la deficiencia enzimática podrían tener una protección parcial contra dicha enfermedad ${ }^{1,2}$.

La G6PD participa del ciclo de las pentosas, cuyo objetivo es producir energía como NADPH (Nicotinamida adenina dinucleótido fosfato), para permitir reacciones de oxidoreducción en las diferentes células del organismo. El GR depende exclusivamente de este mecanismo para obtener energía. Al existir la deficiencia enzimática, y en contacto con oxidantes, el hematíe no es capaz de revertir la reacción y se produce la hemólisis ${ }^{1,2,4,5}$ (figura 1). En glóbulos rojos normales la enzima opera sólo en un $1 \%$ de su potencia máxima frente a un stress oxidativo, es decir, existe un gran potencial reductivo.

La deficiencia de la G6PD tiene un patrón típico de herencia ligado al cromosoma X. Homocigotos y heterocigotos pueden ser sintomáticos aunque la enfermedad es más severa en pacientes que son homocigotos para la deficiencia ${ }^{2}$. La mutación genética que afecta a la G6PD se encuentra en el brazo largo del cromosoma X identificándose más de 140 mutaciones ${ }^{2}$.

Las variantes de la deficiencia fueron agrupadas en 5 clases basados en la actividad en- zimática y manifestaciones clínicas ${ }^{6}$ (tablas 1 y 2). La mayoría de las variantes ocurren en forma esporádica, aunque la forma mediterránea y la G6PD A son más frecuentes en ciertas poblaciones (tabla 2). En algunas de estas variantes se produce hemolisis crónica denominada "hemolisis congénita no esferocitica", esta variante se ha descrito como clase 1 según la clasificación de la OMS (tabla 1). La hemolisis es de tipo extravascular a diferencia de la presentación hemolítica aguda, donde la hemolisis es preferentemente intravascular ${ }^{1}$. Dos nuevas mutaciones son descritas en el trabajo del grupo de hematología del hospital Luis Calvo Mackenna que se manifiestan como anemia hemolítica crónica no esferocitica en niños chileno las cuales son G6PD Santiago y G6PD Luis Calvo Mackenna ${ }^{4}$.

$\mathrm{El}$ diagnóstico de la deficiencia de la G6PD se puede realizar por análisis cuantitativo espectrofotométrico o más comúnmente por un test rápido de fluorescencia el cual detecta la

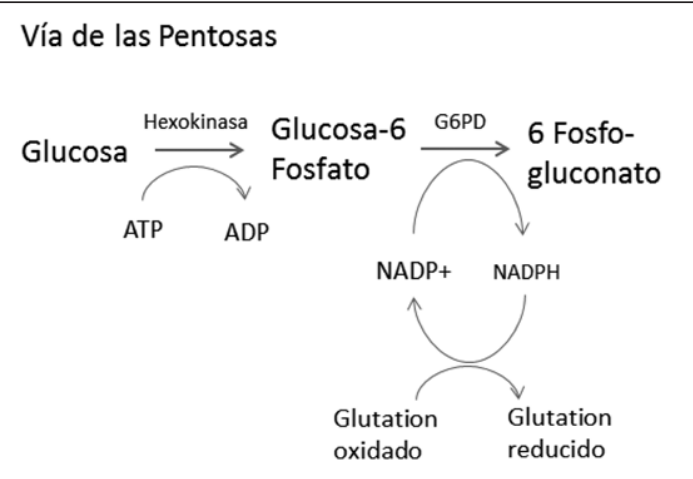

Figura 1. Ciclo de las Pentosas y producción de Nicotinamida Adenina Dinucleotido Fosfato (NADPH). 
Tabla 1. Clase de variantes enzimáticas en glucosa 6-fosfato deshidrogenasa

\begin{tabular}{|ccll|}
\hline Clase & $\begin{array}{c}\text { Nivel de } \\
\text { deficiencia }\end{array}$ & Actividad enzimática & Prevalencia \\
\hline I & Severa & Anemia hemolítica crónica no esferocítica & Poco común \\
II & Severa & Menos del 10\% de lo normal & $\begin{array}{l}\text { Varía; Más frecuente en poblaciones del Mediterráneo y } \\
\text { Asiática }\end{array}$ \\
III & Moderada & 10 al $60 \%$ de lo normal & $10 \%$ del género masculino en la raza negra de USA \\
IV & Leve a ninguna & 60 a $150 \%$ de lo normal & Rara \\
V & Ninguna & $>150 \%$ de lo normal & Rara \\
\hline
\end{tabular}

Frank J: Diagnosis and Management of G6PD Deficiency. American Family Physicians. 2005; 72: 1277-82.

Tabla 2. Comparación de las dos variantes más comunes de deficiencia de glucosa 6-fosfato deshidrogenasa (G6PD)

\begin{tabular}{|lll|}
\hline & G6PD Mediterráneo & G6PD A- \\
\hline Clase de la Organización Mundial de la Salud (WHO) & Clase II & Clase III \\
Poblaciones afectadas & $\begin{array}{l}\text { Italiana, griega, española, arábica, } \\
\text { Descendientes judíos }\end{array}$ & Descendientes africanos \\
\hline Hiperbilirrubinemia neonatal & Si; puede ser severa & Si \\
Favismo & $\mathrm{Si}$ & $\mathrm{Si}$ \\
Hemolisis con drogas oxidativas & $\mathrm{Si}$ & $\mathrm{Si}$ \\
\hline
\end{tabular}

Frank J: Diagnosis and Management of G6PD Deficiency. American Family Physicians. 2005; 72: 1277-82.

generación de NADPH desde NADP. Existe también el test basado en detectar mutaciones específicas a través de PCR usado en detección poblacional, estudios de familias o diagnóstico prenatal.

En la hemolisis aguda los exámenes podrían no detectar la deficiencia debido a que los eritrocitos más viejos han sido destruidos y quedan los más inmaduros y reticulocitos los cuales pueden tener una actividad enzimática normal. Las mujeres heterocigotos debido al mosaicismo del cromosoma $\mathrm{X}$ pueden tener deficiencia parcial y no ser detectado por exámenes de rastreo.

La presentación clínica de esta patología es variable, manifestándose como crisis hemolítica, siendo la más clásica el favismo; de forma crónica no esferocitica y como hiperbilirrubinemia neonatal ${ }^{1-4}$.

\section{Objetivo}

Presentar el caso de un niño que debutó como crisis hemolítica debida a favismo.

\section{Caso clínico}

Varón, 2 años y 7 meses. Primer hijo embarazo con diabetes mellitus insulino dependiente controlada. Edad gestacional 39 semanas, peso de nacimiento: $3.015 \mathrm{~g}$, talla: $49,5 \mathrm{~cm}$, madre e hijo con igual grupo sanguíneo O IV $(+)$. Antecedente de hospitalización 8 días en el período neonatal por hiperbilirrubinemia de $25,1 \mathrm{mg} / \mathrm{dL}$ sin causa evidente. Sin otras morbilidades.

Comenzó en forma brusca con decaimiento, palidez progresiva, dolor abdominal, fiebre y vómitos. Consultó en su hospital de origen, objetivándose palidez importante, ictericia y taquicardia (156 x min). Exámenes iniciales revelaron anemia: Hematocrito (Hto): 18\%, hemoglobina $(\mathrm{Hb}): 5,8 \mathrm{gr} / \mathrm{dL}$ GR: 2,0 x millón/uL poiquilocitosis leve y policromatofilia leve a moderada. Leucocitos: $15.200 \mathrm{x} \mathrm{mm}^{3}$, plaquetas $399.000 \times \mathrm{mm}^{3}$, bilirrubina total: 4,9 $\mathrm{mg} / \mathrm{dL}$ bilirrubina indirecta: 4,6 mg/dL, GOT: 76,3 IU/L GGT: 25,7 IU/L, proteína c reactiva (PCR): $5,3 \mathrm{mg} / \mathrm{L}$, creatininemia: $0,27 \mathrm{mg} / \mathrm{dL}$. 
Tabla 3. Exámenes de laboratorio

\begin{tabular}{|lccrcc|}
\hline & $\begin{array}{c}\text { Día 1 } \\
(\mathbf{0} \text { h) }\end{array}$ & $\begin{array}{c}\text { Día 1 } \\
(\mathbf{1 2} \text { h) } \mathbf{~ T x}\end{array}$ & Día 2 & Día 7 & Día 30 \\
\hline Hto & 18 & 15,8 & 26,9 & 36,5 & 40 \\
Hb & 5,8 & 4,7 & 8,5 & 11,9 & 13,6 \\
VCM & 89 & 91,3 & 88,5 & 87 & 82,5 \\
CHCM & 30 & 29,7 & 31,5 & 32,6 & 34 \\
\hline R & NR & 4,4 & 11,6 & 9,9 & 1,9 \\
GB & 15,2 & 15,5 & 8,2 & 5,7 & 7,9 \\
\hline
\end{tabular}

Hto: hematocrito (\%); Hb: hemoglobina (g/dL); VCM: volumen corpuscular medio (fL); $\mathrm{CHCM}$ : concentración de hemoglobina corpuscular media (g/dL); R: reticulocitos (\%); GB: glóbulos blan-

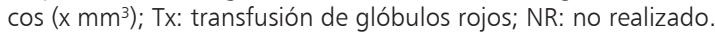

La ecotomografía abdominal mostro hepatomegalia leve y dilatación de vía biliar mínima.

Se derivó a unidad de cuidados críticos pediátricos. En los exámenes de ingreso destacaba anemia severa, Hto: 15,8\% y Hb: 4,7 gr/dL, al frotis: anisocitosis, policromatofilia, poiquilocitosis moderada y regular cantidad de hematíes en mascada, reticulocitos: $4,4 \%$, velocidad de sedimentación (VHS) $17 \mathrm{~mm} / \mathrm{hr}$. Bilirrubina total: $4,11 \mathrm{mg} / \mathrm{dL}$, indirecta: $3,52 \mathrm{mg} / \mathrm{dL}$. En el resto de los exámenes de laboratorio destacaban función renal y hepática normal, y Test de Coombs directo negativo (tabla 3 ).

El paciente había ingerido habas frescas 48 $\mathrm{h}$ previo al inicio de los síntomas, sin ingesta de fármacos. Se planteó como diagnóstico anemia hemolítica no inmune, probable Favismo. Se manejó con hidratación intravenosa con volúmenes altos, se transfundió con glóbulos rojos $10 \mathrm{cc} / \mathrm{kg}$ y ácido fólico oral.

Post transfusión quedó con Hto: 25\%, Hb: $8,1 \mathrm{gr} / \mathrm{dL}$, reticulocitos: $11,6 \%$. A las $48 \mathrm{~h}$ se mantenía estable con persistencia de los reticulocitos elevados $14,2 \%$. Test de detección cualitativo de G6PD (Tonz y Betke) confirmó la deficiencia de la enzima. Evolucionó en buenas condiciones generales y al mes del debut se encontraba sin anemia ni signos de hemolisis.

\section{Discusión}

La mayoría de los pacientes con deficiencia de G6PD son asintomáticos a través de la vida y los casos esporádicos pueden manifestarse como hiperbilirrubinemia incluso desde período neonatal, anemia con signos de hemolisis, dolor abdominal, dolor dorsal, esplenomegalia transitoria, hemoglobinuria e ictericia de escleras. La ictericia no aparece hasta que el $50 \%$ de los eritrocitos se hayan lisado. En el laboratorio se encuentra ictericia de predominio indirecto, aumento de la LDH, anemia moderada o severa de tipo normocítica-normocrómica, células "en mascada" al frotis, reticulocitos elevados, aparición de cuerpos de Heinz después de 7 días de la hemolisis, disminución de la haptoglobina, Test de Coombs directo negativo y pruebas de función hepática normal. La causa mediante la cual la deficiencia de G6PD produce ictericia no es completamente conocida y mecanismos como disminución de la conjugación de la bilirrubina podrían estar jugando un rol concomitante además de la hemolisis.

En período neonatal debería sospecharse en aquellos pacientes que presenten hiperbilirrubinemia dentro de las primeras $24 \mathrm{~h}$ de vida e historia de ictericia en algún hermano ${ }^{2,7}$. En algunas ocasiones la bilirrubina puede llegar a niveles tan altos que requieren fototerapia o exanguineo transfusión, llegando incluso a provocar kernicterus y muerte ${ }^{2,7}$.

La hemolisis aguda puede ser causada por infección, ingestión de habas y exposición a agentes oxidantes como algunos fármacos (tabla 4). Ésta ocurre después de la exposición al agente pero no continúa a pesar de que persista el evento gatillante debido a que la hemolisis inicial es causada por la lisis de los eritrocitos más viejos y más deficientes en la enzima. La infección es probablemente la causa más frecuente de hemolisis en personas con déficit de la G6PD. La hepatitis A y B, Citomegalovirus, neumonía y fiebre tifoidea se describen como las más frecuentes ${ }^{2}$.

Una de las formas de presentación clásica de la deficiencia es el Favismo, siendo más frecuente en personas con déficit de G6PD clase II (Mediterránea) y con menor frecuencia ocurre en pacientes con la variante G6PD $\mathrm{A}^{2,4,6}$. Las habas se presume que causan daño oxidativo conteniendo la Vicina y la Convicina, dos glucósidos que se hidrolizan en el tubo digestivo y 
Tabla 4. Drogas y químicos asociados con hemólisis en pacientes con deficiencia de glucosa 6-fosfato deshidrogenasa

\begin{tabular}{|c|c|c|c|}
\hline & Relación directa & Relación posible & Relación dudosa \\
\hline Antimaláricos & $\begin{array}{l}\text { Primaquina } \\
\text { Pamaquina }\end{array}$ & $\begin{array}{l}\text { Cloroquina } \\
\text { Sulfadimidina } \\
\text { Sulfasalazina } \\
\text { Glibenclamida }\end{array}$ & $\begin{array}{l}\text { Mepacrina } \\
\text { Quinina }\end{array}$ \\
\hline Sulfonamidas & $\begin{array}{l}\text { Sulfanilamida } \\
\text { Sulfacetamida } \\
\text { Sulfapiridina } \\
\text { Sulfametoxazol }\end{array}$ & & $\begin{array}{l}\text { Sulfadiazina } \\
\text { Sulfafurazol }\end{array}$ \\
\hline Sulfones & Dapsona & & $\begin{array}{l}\text { Paracetamol } \\
\text { Fenacetinas }\end{array}$ \\
\hline Nitrofurantoína & Nitrofurantoína & & \\
\hline Antipiréticos o analgésicos & Acetalinida & Aspirina & \\
\hline Otras drogas & $\begin{array}{l}\text { Acido nalidíxico } \\
\text { Niridazol } \\
\text { Azul de metileno } \\
\text { Co-trimoxazol }\end{array}$ & $\begin{array}{l}\text { Ciprofloxacino } \\
\text { Cloranfenicol } \\
\text { Vitamina K } \\
\text { Acido ascórbico } \\
\text { Mesalazina }\end{array}$ & $\begin{array}{l}\text { Ácido amino salicílico } \\
\text { Doxorrubicina } \\
\text { Probenecid } \\
\text { Dimercaprol }\end{array}$ \\
\hline Otros químicos & $\begin{array}{l}\text { Naftaleno } \\
2,4,6 \text {-Trinitrotolueno }\end{array}$ & Extracto de acalifa & \\
\hline
\end{tabular}

Tabla modificada. Cappellini MD y cols 2008 y Frank J 2005.

se convierten en divicina e isouramilo respectivamente, los cuales son capaces de producir hemolisis de los GR en personas que tengan déficit de la G6PD. No todos los pacientes con la enfermedad responden igual después de la ingesta de habas, incluso el mismo individuo puede tener una respuesta impredecible, lo cual hace pensar que existen otros factores que influyen como el estado de salud del paciente o la cantidad de habas ingerida. La enfermedad se presenta con más frecuencia en el período de cosecha con habas frescas, y también cuando están secas o congeladas. Incluso niños con lactancia materna pueden presentar hemolisis si la madre ha consumido habas, ésta se puede presentar $24 \mathrm{~h}$ posteriores a la ingesta.

La hemoglobinuria que se presenta en el favismo es más intensa que la que se observa secundario a drogas o infección; aunque la bilirrubina es menor, la anemia es aguda y severa llevando a la falla renal en algunos pacientes. El daño oxidativo que sufren los eritrocitos les provoca una serie de alteraciones que los llevan rápidamente a ser retirados de la circulación. Por esta razón la hemolisis observada en estos pacientes es de tipo intra y extravascular. Las personas con deficiencia de la enzima es- tán más expuestas a sepsis y sus complicaciones después de una injuria severa.

Con respecto al manejo de la deficiencia de la G6PD, se basa en prevenir la hemolisis evitando los agentes oxidantes conocidos, para lo cual el paciente debe conocer su enfermedad y estar al tanto de los medicamentos y alimentos que no debe consumir. Afortunadamente la hemolisis por lo general es de corta duración y no requiere tratamiento especifico excepto en aquellos niños en que la hemolisis haya desencadenado una anemia severa y requiera transfusión de GR. Los pacientes que cursan en forma crónica deben ser controlados, ya que pueden presentar crisis hemolíticas, y pueden desarrollar esplenomegalia, pero no se benefician con la esplenectomía. La litiasis vesicular es una posible complicación. En general los pacientes no tienen dependencia transfusional y no afecta la expectativa de vida ni la calidad de ésta.

Nuestro paciente presentó hiperbilirrubinemia neonatal debutando posteriormente con una anemia hemolítica severa desencadenada por la ingesta de habas, lo que hizo sospechar el diagnóstico de favismo asociado a la presencia de GR en mascada al frotis. 


\section{Conclusiones}

A pesar que la deficiencia de la G6PD no es una patología frecuente en pediatría podría aumentar por la alta inmigración que ha sufrido nuestro país y debería ser sospechada en aquellos recién nacidos varones que presenten hiperbilirrubinemia de aparición precoz, sin incompatibilidad a grupo clásico ni a grupo $\mathrm{Rh}$, con antecedentes familiares de anemia hemolítica y consanguinidad paterna y también en aquellos pacientes que presenten hemolisis no inmune en relación a infecciones, drogas que causen oxidación en el GR y por la ingesta de habas.

\section{Referencias}

1.- CappelIini MD, Fiorelli G: Glucose-6-phosphate dehydrogenase deficiency. Lancet 2008; 371: 64-74.

2.- Frank J: Diagnosis and Management of G6PD Deficien- cy. American Family Physicians 2005; 72: 1277-82.

3.- Schuurman M, Waardenburg D, Da Costa J, Niemarkt $H$, Leroy P: Severe hemolysis and Metahemoglobinemia following fava beans ingestion in glucose-6phosphatase dehydrogenase deficiency-case report and literature review. Eur J Pediatr 2009; 168: 779-82.

4.- Dal Borgo P, Silva R, Cavieres M: Dos nuevas mutaciones de glucose 6 fosfato deshidrogenasa, G6PD Santiago y G6PD Calvo Mackenna. Rev Chil Pediatr 2000; 71 (5): 419-22.

5.- Yang Y, Li Z, Nan P, Zhang X: Drug-induced glucose-6phosphate dehydrogenase deficiency-related hemolysis risk assesment. Computational Biology and Chemistry 2011; 35: 189-92.

6.- WHO working group: Glucose-6-phosphate dehydrogenase deficiency. Bull World Health Organ 1989; 67: 601-11.

7.- Abdel M, Abdel E, Adel A, Mosallam D: Glucose-6Phosphate Dehydrogenase and Red Cell Pyruvate Kinase Deficiency in Neonatal Jaundice Cases in Egypt. Pediatric Hematology and Oncology 2010; 27: 262-71. 